\title{
Examining the predictive capabilities of a bounding surface plasticity-based hyperelastic constitutive model for unsaturated granular soils
}

\author{
Mehdi Kadivar $^{1}$, Kalehiwot Nega Manahiloh ${ }^{2, *}$, and Victor N. Kaliakin ${ }^{3}$ \\ ${ }^{1}$ Department of Engineering, Cambridge University, Civil Engineering Building 7a, JJ Thomson Avenue, Cambridge, UK, CB3 0FA \\ ${ }^{2} 800$ West University Parkway, Department of Engineering, Utah Valley University, Orem, UT, USA, 84058 \\ 3301 DuPont Hall, Department of Civil and Environmental Engineering, University of Delaware, Newark, DE, USA, 19716
}

\begin{abstract}
The performance of a recently developed state-dependent constitutive model for unsaturated granular soils is evaluated. The model employs the Bounding Surface plasticity framework and evaluates elastic strains assuming hyperelastic behavior. To realistically simulate the deformation of unsaturated granular soils, the mechanical behavior was modeled without a purely elastic component. The inherent hydromechanical coupling was realized by introducing a Bishop-type effective stress, an appropriate workconjugate variable, and a soil-water characteristic curve function. Relevant details about the model development, parameter estimation, and the assessment of the model's predictive capabilities are presented. The model performance is evaluated with experimental data obtained for drained and constant-water stress paths. With a given a set of parameter values, the model realistically simulates the main features that characterize the shear and volumetric behavior of unsaturated granular soils over a wide range of matric suction, density, and net confining pressure. This is found to be true for both drained and constant-water stress paths.
\end{abstract}

\section{Introduction}

Environmental conditions control the depth of the groundwater table and, therefore, the thickness of the unsaturated soil zone; i.e., the zone between the ground surface and the water table. In this zone, the pore-water pressure is negative. It can range from a minimal magnitude near the water table to values approaching $1,000,000 \mathrm{kPa}$ [1]. Studies report that, in the USA alone, problems associated with unsaturated soils (e.g., volume change, pressure generation, and moisture transport) annually inflict an estimated $\$ 15$ billion in damage to buildings, roads, and pipelines [2].

Constitutive modeling of unsaturated soils began in the 1990s. Research in this field was pioneered by Alonso et al. [3], who extended the modified Cam-Clay model [4] to develop an elasto-plastic model based on the concept of two independent stress state variables. In the two independent stress state variable concept [5], the behavior of unsaturated soils is governed by the matric suction and net stress. Based on the concept of two stress state variables, several constitutive models were subsequently developed and used to simulate the behavior of unsaturated soils [e.g., 6, 7, 8]. However, Gens et al. [9] postulated that the framework of two independent stress state variables gives acceptable results only in cases when one of the variables is kept constant. Nuth and Laloui [10], argued that separating the mechanical stress from the hydraulic stress prevents the appropriate simulation of the hydro-mechanical coupling phenomenon observed in unsaturated soils. Sheng [11] indicated that in the twostress state variable approach there is a discontinuity at the transition between saturated and unsaturated states. By using energy principles, Houlsby [12] demonstrated that two sets of stress-strain variables (i.e., effective stress and matric suction as stress variables, and the strain of solid skeleton and degree of saturation as kinematic variables) are adequate to describe unsaturated soil behavior. Houlsby's explanation was consistent with the Bishoptype [13] effective stress approach, which has been extensively used to describe unsaturated soil behavior [14-24].

The effective stress framework enables the direct incorporation of the soil water characteristic curve (SWCC) and the intrinsic hysteresis. This characteristic makes the effective stress-based framework a viable choice when implementing an unsaturated soil constitutive model into a commercial or research finite element computer program. As most existing finite element programs for geotechnical analyses are written for saturated soils, a natural transition to unsaturated states would thus be realized by simply replacing Terzaghi's effective stress with a Bishop-type effective stress [10].

In this paper, a state-dependent constitutive model that can describe the mechanical behavior of granular soils is assessed for performance under different stress paths. The model is based on the bounding surface plasticity

\footnotetext{
* Corresponding author: kmanahiloh@uvu.edu
} 
framework and incorporates a newer generation of Bishop's effective stress concept. The model is an extension of an existing hyperelastic model, which was originally proposed by Lashkari et al. [25] for simulating the elastoplastic behavior of fully saturated granular soils. In this model, elastic strains are computed from the Gibbs free energy. Consequently, the conservation of energy is fully satisfied. Using a single set of parameter values, the present model predicts the behavior of unsaturated granular soils with various ranges of density, normal stresses, and matric suction. The model's performance is assessed by comparing its simulations with experimental data for clean sand following drained and constant-water stress paths.

\section{Model development}

Consistent with Zhang and Lytton [26] and Sheng et al. [27], who showed that for unsaturated soils the elastic volumetric change is stress-path dependent, and following the work of Maier and Hueckel [28] and Collins and Houlsby [29], who postulated that elastic behavior is affected by the plastic strains, coupled elastic-plastic strain rates are added to the elastic strain rates. The elastic strain rate is therefore decomposed into reversible and irreversible (coupled) portions. It should be noted that due to the stress path dependency of the elastic behavior of unsaturated soils, in the present model no purely elastic strains can develop at any time. The main components of the model within axisymmetric triaxial space, in terms of the mean normal effective stress $\left(p^{\prime}\right)$ and the deviator stress $(q)$, are summarized below.

\subsection{Summary of components of base model} (Kadivar et al., 2020)

\subsubsection{Effective Stress Definition}

$$
\begin{gathered}
\boldsymbol{\sigma}^{\prime}=\left\{\begin{array}{c}
p^{\prime} \\
q
\end{array}\right\}=\left\{\begin{array}{c}
p_{\text {net }}+\chi s \\
q
\end{array}\right\} \\
\chi=S_{r e}=\frac{\left\langle S_{r}-S_{r 0}\right\rangle}{1-S_{r 0}}
\end{gathered}
$$

In Equation (1), $p_{\text {net }}$ is the net confining stress, $s$ is the matric suction, $\chi$ is the Bishop effective stress parameter, $S_{r e}$ is the so-called relative degree of saturation, $S r$ is the degree of saturation, and $S_{r 0}$ is the residual state degree of saturation, which can be estimated from the SWCC, and the symbols represent Macaulay brackets.

\subsubsection{Soil Water Characteristic Curve}

$$
\begin{gathered}
S_{r}=S_{r 0}+\left(1-S_{r 0}\right)\left(1-\frac{\ln \left(1+\frac{s}{s_{0}}\right)}{\ln \left(1+\frac{10^{6}}{s_{0}}\right)}\right)\left[\ln \left(\exp (1)+\left(\frac{s^{*}}{a_{v} \cdot p_{r e f}}\right)\right)^{n_{v}}\right]^{-m_{v}} \\
S^{*}=S e^{\Omega}
\end{gathered}
$$

where $a_{v}, n_{v}, m_{v}$, and $\Omega$ are model parameters, and $s_{0}$ is the residual values of the degree of saturation.

\subsubsection{Strain Decomposition}

$$
\left\{\begin{array}{l}
\varepsilon_{v} \\
\varepsilon_{q}
\end{array}\right\}=\left\{\begin{array}{l}
\varepsilon_{v} \\
\varepsilon_{q}
\end{array}\right\}^{e r}+\left\{\begin{array}{l}
\varepsilon_{v} \\
\varepsilon_{q}
\end{array}\right\}^{i}=\left\{\begin{array}{c}
\varepsilon_{v} \\
\varepsilon_{q}
\end{array}\right\}^{e r}+\left\{\begin{array}{c}
\Gamma_{, p X} X_{, \eta} K_{p} \dot{\boldsymbol{\varepsilon}}_{q}^{p}+\dot{\boldsymbol{\varepsilon}}_{v}^{p} \\
\left(\Gamma_{, q X} X_{, \eta} K_{p}+1\right) \dot{\boldsymbol{\varepsilon}}_{q}^{p}
\end{array}\right\}
$$

where, $\varepsilon_{\mathrm{v}}$ and $\varepsilon_{\mathrm{q}}$ are the volumetric and distortional components, respectively, of the infinitesimal strain vector, the superscripts "er" and " $i$ " stand for "elastic reversible" and "irreversible", respectively, $\Gamma$ is the Gibbs free energy function, given by Eq. (8), and $\Gamma_{, p \mathrm{X}}=\partial^{2} \Gamma / \partial p^{\prime} \partial \mathrm{X}, \Gamma_{, q \mathrm{X}}=\partial^{2} \Gamma / \partial q \partial \mathrm{X}$, and $\mathrm{X}_{, \eta}=\partial \mathrm{X} / \partial \eta$.

\subsubsection{Elastic stiffness matrix}

$$
\left\{\begin{array}{c}
\dot{p}^{\prime} \\
\dot{q}
\end{array}\right\}=\left[\begin{array}{cc}
K & J \\
J & 3 G
\end{array}\right]\left\{\begin{array}{c}
\dot{\varepsilon}_{v} \\
\dot{\varepsilon}_{q}
\end{array}\right\}^{e r}
$$

where $K, G$, and $J$ are the hyperelastic moduli.

\subsubsection{Hyper-elastic moduli}

$$
\begin{aligned}
& K=\frac{1}{1-\frac{X(X-1)}{6} \cdot\left(\frac{K_{0}}{G_{0}}\right) \cdot \eta^{2}} K_{0} p_{r e f} F(e)\left(\frac{p^{\prime}}{p_{\text {ref }}}\right)^{X} \\
& G=\frac{1}{1-\frac{X(X-1)}{6} \cdot\left(\frac{K_{0}}{G_{0}}\right) \cdot \eta^{2}}\left(G_{0} F(e)+\frac{X(X+1)}{6} K_{0} F(e) \eta^{2}\right) \\
& G_{0} p_{r e f} F(e)\left(\frac{p^{\prime}}{p_{r e f}}\right)^{X} \\
& J=\frac{1}{1-\frac{X(X-1)}{6} \cdot\left(\frac{K_{0}}{G_{0}}\right) \cdot \eta^{2}} X \eta K_{0} p_{r e f} F(e)\left(\frac{p^{\prime}}{p_{r e f}}\right)^{X}=X:
\end{aligned}
$$

where, $K_{0}$ and $G_{0}$, are model parameters, $p_{\text {ref }}$ is the atmosphere pressure, $X$ is the elastic variable, which evolves with plastic hardening as defined by Eq. (7), $\eta=$ $q / p^{\prime}$ is the stress ratio, and $F(e)$ is a function of the void ratio $(e)$ and particle shape. For granular soils with angular particles, $F(e)=(2.97-e)^{2} /(1+e)$; for similar soils with well-rounded particles, $F(e)=(2.17-e)^{2} /(1+e)$.

\subsubsection{Gibbs free energy function}

$$
\begin{aligned}
& \Gamma(p, q, X)=\frac{p^{2-X}-(2-X) p p_{0}^{1-X}}{K_{0} F(e)(2-X)(1-X) p_{r e f}^{1-X}}+ \\
& \frac{q^{2}}{6 G_{0} F(e) p^{X} p_{r e f}^{1-X}}-\frac{q_{0}\left(2 q p_{0}-X q_{0} p\right)}{6 G_{0} F(e) p_{0}^{1+X} p_{r e f}^{1-X}}
\end{aligned}
$$

where, $p_{0}$ and $q_{0}$ are the values of $p^{\prime}$ and $q$ at zero elastic strain, respectively. 


\subsubsection{Elastic variable}

$$
X=X(\eta)=X_{\text {min }}+\frac{X_{\max }-X_{\min }}{1+B\left[\left(\frac{M}{\eta}\right) \exp \left(-n^{b} \psi\right)-1\right]}
$$

where, $X_{\max }=0.95, X_{\min }=0.50$, and $B=0.10$; these values apply to any soil [25].

\subsubsection{Bounding surface}

$$
M^{b}=M \exp \left(-n^{b} \psi\right)
$$

where $M$ is the slope of the critical state line (CSL) in $p^{\prime}-q$ space that takes on values of $M_{\mathrm{c}}$ and $M_{\mathrm{e}}$ for axisymmetric triaxial compression and extension, respectively, $n^{b}$ is a model parameter, and $\psi$ is the Been and Jefferies state parameter [30] that represents the state dependency of the model by relating the current void ratio of a soil $(e)$ with its value at critical state $\left(e_{\mathrm{c}}\right)$ according to $\psi=e-e_{\mathrm{c}}$.

\subsubsection{Dilatancy surface}

$$
M^{d}=M \exp \left(n^{d} \psi\right)
$$

where, $n^{d}$ is a model parameter

\subsubsection{Flow rule}

$$
\dot{\varepsilon}_{q}^{p}=\langle\Lambda\rangle \frac{\dot{\eta}}{K_{p}}
$$

where $\Lambda$ is a scalar loading index, $\eta$ is again the stress ratio, and $K_{p}$ is the dimensionless plastichardening modulus.

\subsubsection{Loading index}

$$
\Lambda=\frac{(3 G-J \eta) \dot{\varepsilon}_{q}+(J-K \eta) \dot{\varepsilon}_{v}}{p K_{p}+\left(1+\Gamma_{, q X} \mathrm{X}_{, \eta} K_{p}\right)(3 G-J \eta+(J-K \eta) d)}
$$

\subsubsection{Plastic-hardening modulus}

$$
K_{p}=h_{0}\left(1-c_{h} e\right)\left(\frac{M^{b}}{\eta}-1\right)\left(\frac{p_{r e f}}{p}\right)^{1-X}
$$

where $h_{0}$ and $c_{h}$ are dimensionless model parameters, and $e$ is the void ratio.

\subsubsection{Dilatancy function}

$$
d=A^{d}\left[2-\sqrt{\left\langle M^{d}-\eta\right\rangle /(1+c) M}\right]\left(M^{d}-\eta\right)
$$

where, $A_{d}$ is a model parameter and $c=M_{e} / M_{c}$, where $M_{\mathrm{e}}$ and $M_{\mathrm{c}}$ are the values of $M$ in axisymmetric triaxial extension and compression, respectively.

\subsubsection{Critical State Void Ratio}

$$
\begin{gathered}
e_{c}=e_{0}-\lambda\left(\frac{p^{\prime}}{p_{r e f}(1+g(\xi))}\right)^{\zeta} \\
g(\xi)=a \cdot[\exp (b \cdot \xi)-1] \\
\xi=f(s) \cdot\left(1-S_{r}\right) \\
f(s)=1+\frac{s^{0.75}}{2\left(125+s^{0.75}\right)}
\end{gathered}
$$

where, $e_{c}$ is the critical state void ratio, $e_{0}, \lambda, \zeta, a$ and $b$ are model parameters, and $\xi$ is a "cementation" parameter according to Gallipoli et al. [31].

\section{Assessment of predictive capability}

The predictive capacity of the model is examined by comparing its simulations with a set of axisymmetric triaxial test results on clean sand following drained and constant-water stress paths, performed by Russell and Khalili [32]. These researchers performed suctioncontrolled axisymmetric triaxial compression tests on Kurnel sand. The specific gravity of this sand particles $\left(G_{\mathrm{s}}\right)$ is 2.65 , the mean grain size $\left(D_{50}\right)$ is $0.31 \mathrm{~mm}$, the uniformity coefficient $\left(C_{u}\right)$ is 1.83 , and the minimum and maximum void ratios are 0.60 and 0.92 , respectively. Experimental data for the SWCC, along with the best-fit curve given by Eq. (2), are presented in Fig. 1. CSLs in the space of $q$ - $p^{\prime}$ and $e-\left(p^{\prime} / p_{\text {ref }}(1+g(\xi))\right)^{\zeta}$ are shown in Figs. $2 \mathrm{a}$ and $2 \mathrm{~b}$, respectively. The complete set of model parameter values used in simulating the behavior of this sand is presented in Table 2 .

Figs. 3 to 6 compare the model simulations with experimental data at constant matric suction values of 51, 100 , and $200 \mathrm{kPa}$. These tests are performed at net confining stresses ranging between approximately 50 to approximately $100 \mathrm{kPa}$, and the initial void ratios ranging from 0.658 to 0.780 . These figures show that the present model is able to accurately simulate the experimental data of shear strength and volumetric behavior of the soil.

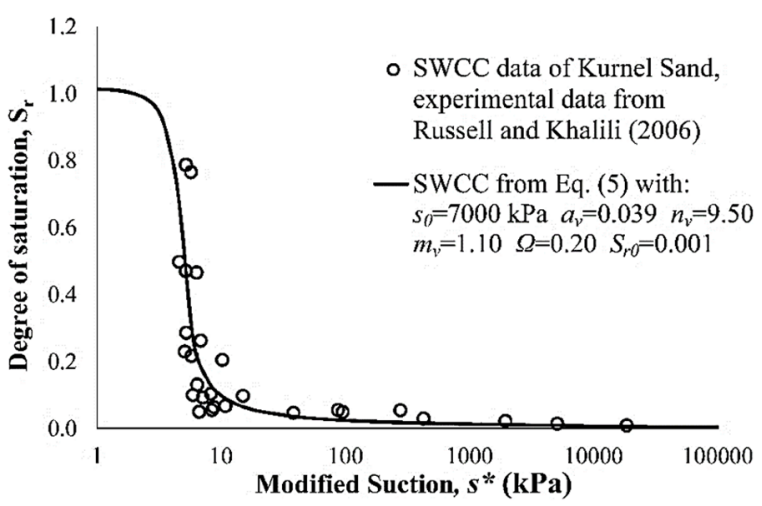

Fig. 1. Experimental and analytical soil-water characteristic curves for Kurnel sand. 
Table 1. Values of model parameters used to simulate the behavior of unsaturated Kurnel sand

\begin{tabular}{c|c}
\hline Value & Model Parameters \\
\hline 250 & $K_{0}$ \\
200 & $G_{0}$ \\
1.422 & $e_{0}$ \\
0.508 & $\lambda$ \\
0 & $a$ \\
0 & $b$ \\
0.07 & $\zeta$ \\
1.77 & $M_{\mathrm{c}}$ \\
0.5 & $n^{b}$ \\
2.7 & $n^{d}$ \\
0.35 & $A^{d}$ \\
95 & $h_{0}$ \\
0.1 & $c_{h}$ \\
\hline
\end{tabular}

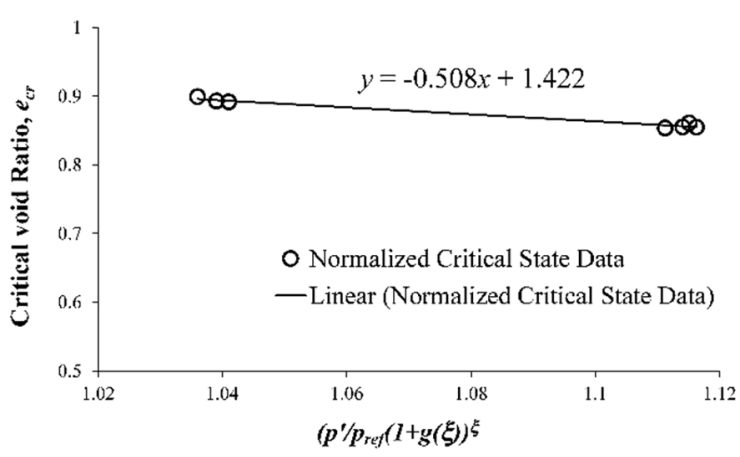

(a)

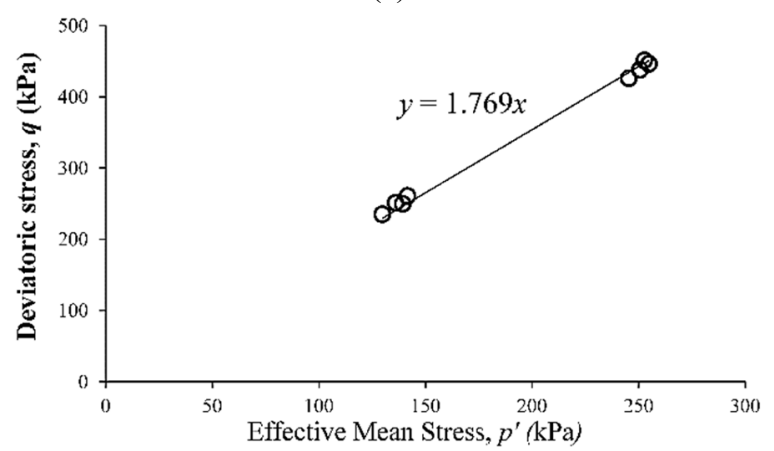

(b)

Fig. 2. Critical state line for unsaturated Kurnel sand in the space of (a) $e-\left(p^{\prime} / p_{r e f}(1+g(\xi))\right)^{\zeta}$ and (b) $q-p^{\prime}$ [experimental data from 32].

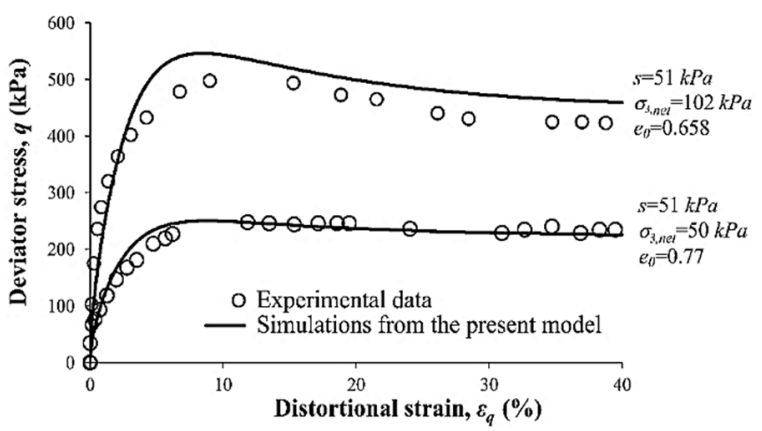

(a)

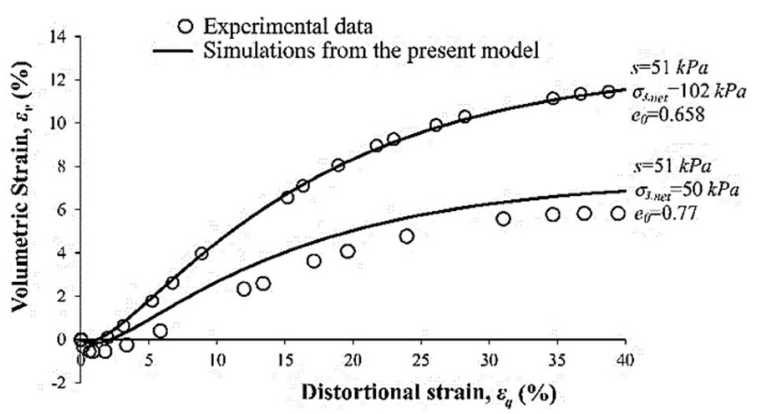

(b)

Fig. 3. Simulation of the experimental data of clean sand at $s=$ $51 \mathrm{kPa}$ : (a) Deviator stress vs. distortional strain, and (b) Volumetric strain vs. distortional strain [experimental data from 32].

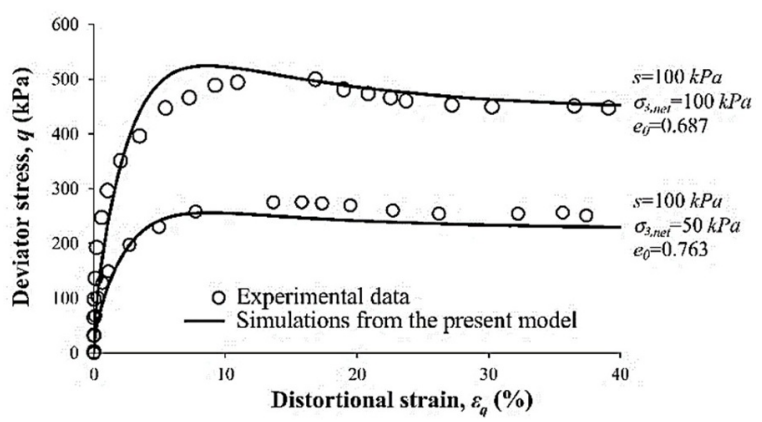

(a)

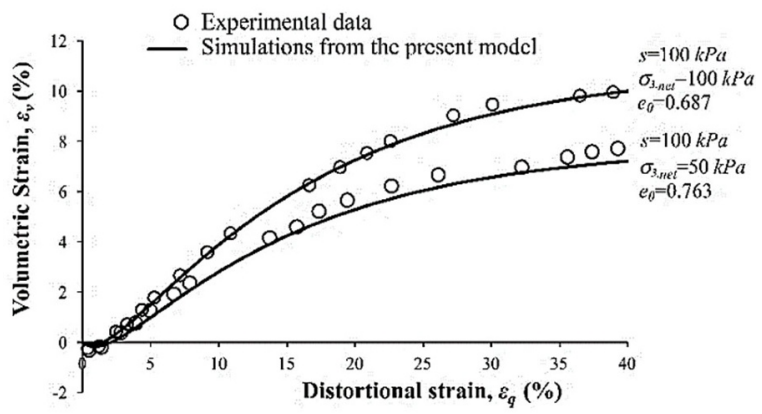

(b)

Fig. 4. Simulation of the experimental data of clean sand at $s=$ $100 \mathrm{kPa}$ : (a) Deviator stress vs. distortional strain, and (b) Volumetric strain vs. distortional strain [experimental data from 32]. 


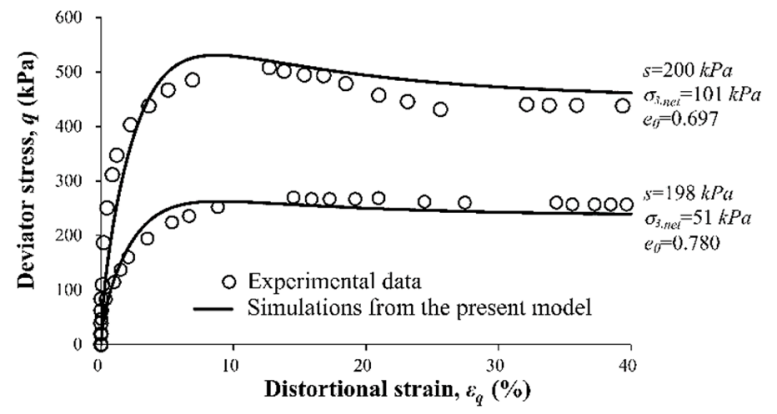

(a)

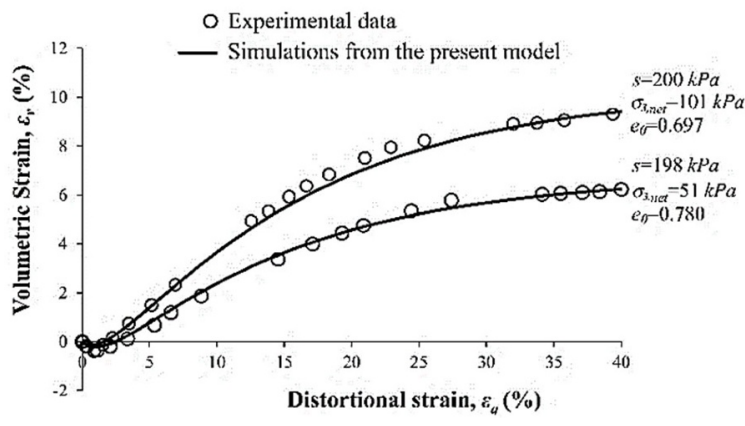

(b)

Fig. 5. Simulation of the experimental data of clean sand at $s=$ $200 \mathrm{kPa}$ : (a) Deviator stress vs. distortional strain, and (b) Volumetric strain vs. distortional strain [experimental data from 32].

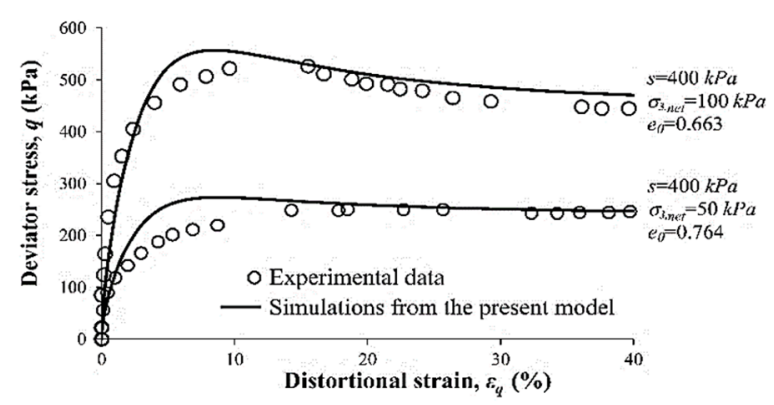

(a)

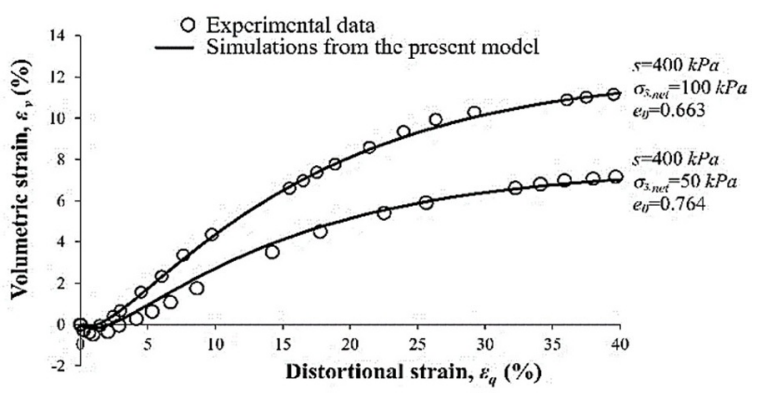

(b)

Fig. 6. Simulation of the experimental data of clean sand at $s=$ $400 \mathrm{kPa}$ (a) Deviator stress vs. distortional strain, and (b) Volumetric strain vs. distortional strain [experimental data from 32].

Russell and Khalili [32] also performed triaxial tests on the Kurnel sand at water constant conditions, while keeping a ratio of $d q / d p_{\text {net }}=3$ during the tests. As the volume of water inside the soil is maintained constant, the matric suction varies due to the volume changes in the soil. From basic soil mechanics:

$$
S_{r} e=G_{s} w
$$

where $G s$ is the specific gravity and $w$ is the water content of the soil. Knowing that $w$ is constant, it follows

$$
d S_{r} e+S_{r} d e=0
$$

where $S_{\mathrm{r}}$ is a function of matric suction and void ratio. The change of degree of saturation is thus related to the changes of matric suction and void ratio according to

$$
d S_{r}=\frac{\partial S_{r}}{\partial s} d s+\frac{\partial S_{r}}{\partial e} d e
$$

Combining Eqs. (16) and (17), the change of matric suction is obtained by integrating the following expression:

$$
d s=-\frac{\left(\frac{S_{r}}{e}+\frac{\partial S_{r}}{\partial e}\right) d e}{\frac{\partial S_{r}}{\partial s}}
$$

Implementing the above correlation into the framework of the present constitutive model, the data of the Kurnel sand at water constant condition are simulated at different initial conditions. The model parameter values given in Table 2 are still valid for the constant-water stress predictions. Figures 7 to 10 compare the model predictions with the experimental data. From these figures, it is evident that the assessed model predicted the response under water constant conditions with reasonable accuracy.

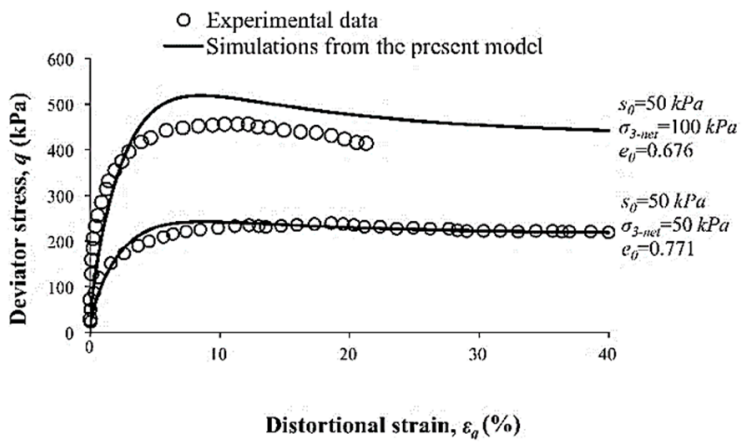

(a)

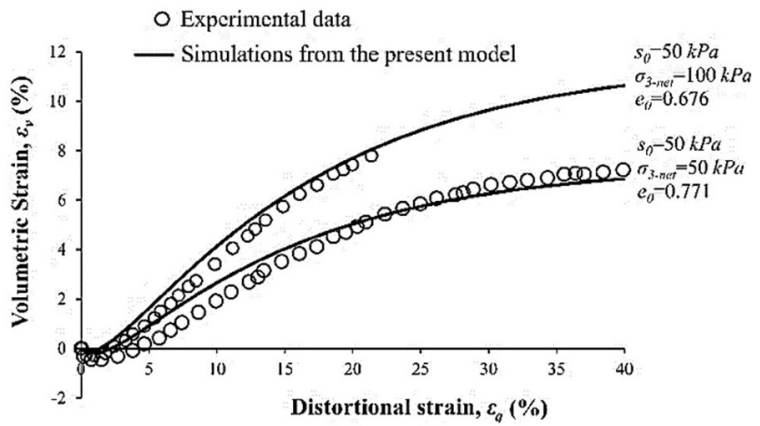

(b)

Fig. 7. Simulation of the experimental data of clean sand at constant water condition at $s_{0}=50 \mathrm{kPa}$ (a) Deviator stress vs. distortional strain, and (b) Volumetric strain vs. distortional strain [experimental data from 32]. 


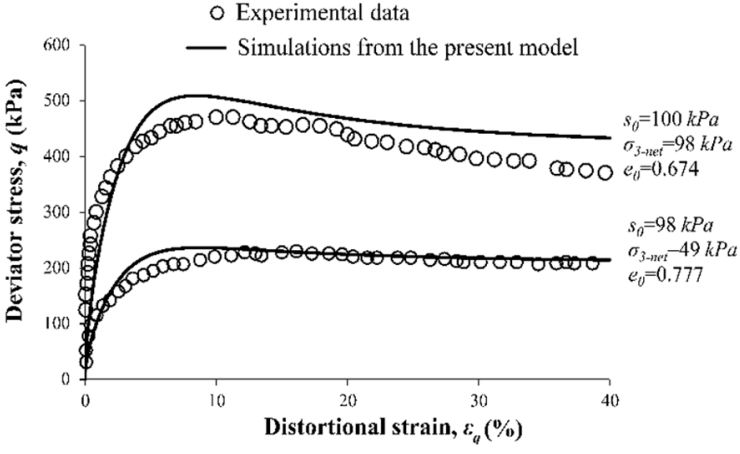

(a)

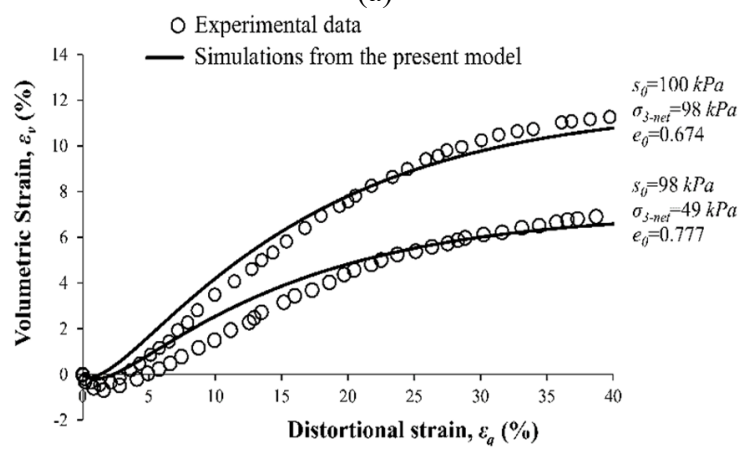

(b)

Fig. 8. Simulation of the experimental data of clean sand at constant water condition at $s 0=100 \mathrm{kPa}$ (a) Deviator stress vs. distortional strain, and (b) Volumetric strain vs. distortional strain [experimental data from 32].

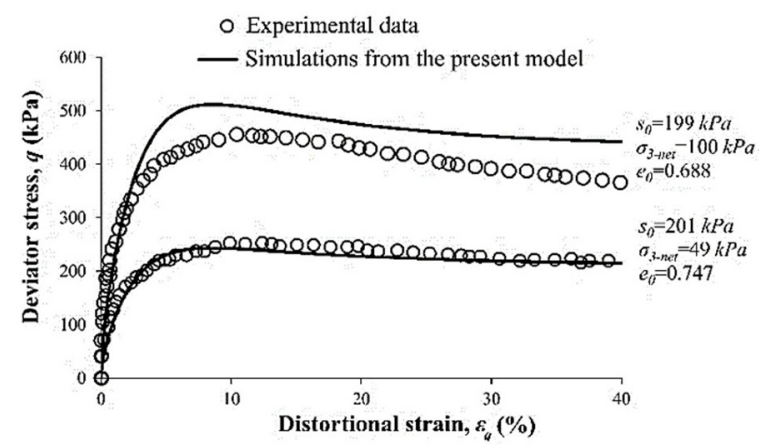

(a)

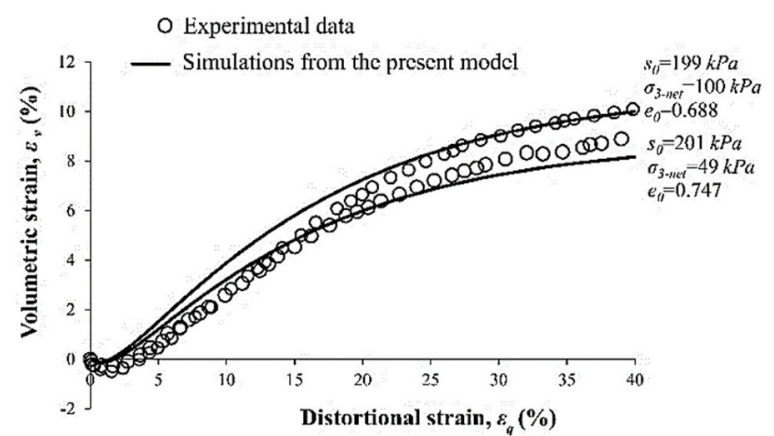

(b)

Fig. 9. Simulation of the experimental data of clean sand at constant water condition at $s 0=200 \mathrm{kPa}$ (a) Deviator stress vs. distortional strain, and (b) Volumetric strain vs. distortional strain [experimental data from 32].

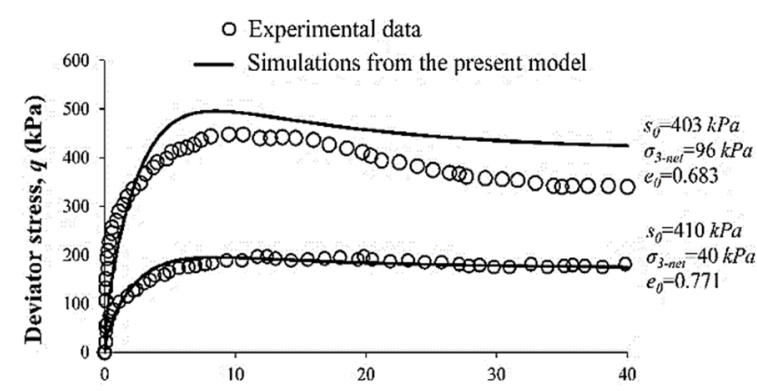

Distortional strain, $\varepsilon_{u}(\%)$

(a)

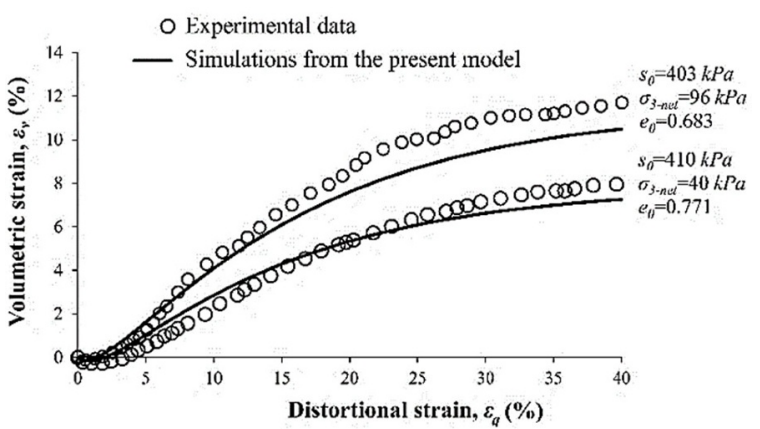

(b)

Fig. 10. Simulation of the experimental data of clean sand at constant water condition at $s_{0}=400 \mathrm{kPa}$ (a) Deviator stress vs. distortional strain, and (b) Volumetric strain vs. distortional strain [experimental data from 32].

\section{Conclusions}

An overview of a recently developed hyperelastic rateindependent bounding surface plasticity model for unsaturated granular soils was presented in this paper. The model is formulated within the traditional effective stress framework. It is state-dependent, critical state compatible, and incorporates the effect of matric suction on the hydromechanical response of unsaturated granular soils. Consistent with the mechanical behavior of unsaturated granular soils, the stress-strain response was assumed to be exclusively elastoplastic, with no purely elastic region. To satisfy the law of conservation of energy, the elastic components of the elastoplastic strains are calculated from a Gibbs free energy function in a hyperelastic formulation. The model was calibrated for a set of unsaturated experimental results for a pure sand following drained and constant-water stress paths. It was shown that the present model is able to accurately predict the behavior of unsaturated granular soils at various levels of initial matric suction, confining pressure and void ratio. The model was assessed for its predictive capabilities of the mechanical behavior of pure sand. Data from drained and constant water triaxial tests were utilized in assessing the predictive capabilities of the model. It was shown that the model satisfactorily captured the stress strain and volume change behaviors of the pure sand. 


\section{References}

1. D.G. Fredlund, H. Rahardjo, and M.D. Fredlund, Soil Mechanics for unsaturated soils. 2012, New York: John Wiley and Sons Inc.

2. W.K. Wray and K.T. Meyer, Geo-Strata -Geo Institute of ASCE, 2004. 5:4: p. 24-28.

3. E.E. Alonso, A. Gens, and A. Josa, A constitutive model for partially saturated soils. Géotechnique, 1990. 40:3: p. 405-430.

4. K.H. Roscoe, On the generalised stress-strain behaviour of wet clay. Engineering Plasticity, 1968: p. 535-609.

5. D.G. Fredlund, N.R. Morgenstern, and R.A. Widger, The shear strength of unsaturated soils. Canadian Geotechnical Journal, 1978. 15:3: p. 313-321.

6. S.J. Wheeler and V. Sivakumar, An elasto-plastic critical state framework for unsaturated soil. Géotechnique, 1995. 45:1: p. 35-53.

7. D. Sheng, D.G. Fredlund, and A. Gens, A new modelling approach for unsaturated soils using independent stress variables. Canadian Geotechnical Journal, 2008. 45:4: p. 511-534.

8. Y.J. Cui and P. Delage, Yielding and plastic behaviour of an unsaturated compacted silt. Géotechnique, 1996. 46:2: p. 291-311.

9. A. Gens, M. Sánchez, and D. Sheng, On constitutive modelling of unsaturated soils. Acta Geotechnica, 2006. 1:3: p. 137.

10. M. Nuth and L. Laloui, Effective stress concept in unsaturated soils: Clarification and validation of a unified framework. International Journal for Numerical and Analytical Methods in Geomechanics, 2008. 32:7: p. 771-801.

11. D. Sheng, Review of fundamental principles in modelling unsaturated soil behaviour. Computers and Geotechnics, 2011. 38:6: p. 757-776.

12. G.T. Houlsby, The work input to an unsaturated granular material. Géotechnique, 1997. 47:1: p. 193196.

13. A.W. Bishop, The principle of effective stress. Tecnisk Ukeblad, 1959. 39: p. 859-863.

14. D. Sheng, S.W. Sloan, and A. Gens, A constitutive model for unsaturated soils: thermomechanical and computational aspects. Computational Mechanics, 2004. 33:6: p. 453-465.

15. D. Sun, D. Sheng, and S.W. Sloan, Elastoplastic modelling of hydraulic and stress-strain behaviour of unsaturated soils. Mechanics of Materials, 2007. 39:3: p. 212-221.

16. D.A. Sun, D.C. Sheng, H.B. Cui, and S.W. Sloan, A density-dependent elastoplastic hydro-mechanical model for unsaturated compacted soils. International Journal for Numerical and Analytical Methods in Geomechanics, 2007. 31:11: p. 1257-1279.

17. B. Loret and N. Khalili, An effective stress elasticplastic model for unsaturated porous media. Mechanics of Materials, 2002. 34:2: p. 97-116.

18. J.-M. Pereira, H. Wong, P. Dubujet, and P. Dangla, Adaptation of existing behaviour models to unsaturated states: application to CJS model. International Journal for Numerical and Analytical
Methods in Geomechanics, 2005. 29:11: p. 11271155.

19. G. Bolzon, B.A. Schrefler, and O.C. Zienkiewicz, Elastoplastic soil constitutive laws generalized to partially saturated states. Géotechnique, 1996. 46:2: p. 279-289.

20. C. Zhou, C.W.W. Ng, and R. Chen, A bounding surface plasticity model for unsaturated soil at small strains. International Journal for Numerical and Analytical Methods in Geomechanics, 2015.39:11: p. 1141-1164.

21. R. Hu, H.-H. Liu, Y. Chen, C. Zhou, and D. Gallipoli, A constitutive model for unsaturated soils with consideration of inter-particle bonding. Computers and Geotechnics, 2014. 59: p. 127-144.

22. D. Manzanal, M. Pastor, and J.A.F. Merodo, Generalized plasticity state parameter-based model for saturated and unsaturated soils. Part II: Unsaturated soil modeling. International Journal for Numerical and Analytical Methods in Geomechanics, 2011. 35:18: p. 1899-1917.

23. D. Mašín and N. Khalili, Swelling phenomena and effective stress in compacted expansive clays. Canadian Geotechnical Journal, 2015. 53:1: p. 134147.

24. S.J. Wheeler, R.S. Sharma, and M.S.R. Buisson, Coupling of hydraulic hysteresis and stress-strain behaviour in unsaturated soils. Géotechnique, 2003. 53:1: p. 41-54.

25. A. Lashkari, A. Karimi, K. Fakharian, and F. Kaviani-Hamedani, Prediction of Undrained Behavior of Isotropically and Anisotropically Consolidated Firoozkuh Sand: Instability and Flow Liquefaction. International Journal of Geomechanics, 2017. 17:10: p. 04017083.

26. X. Zhang and R.L. Lytton, Discussion of "A new modelling approach for unsaturated soils using independent stress variables"Appears in Canadian Geotechnical Journal, 45(4): 511-534. Canadian Geotechnical Journal, 2008. 45:12: p. 1784-1787.

27. D. Sheng, D.G. Fredlund, and A. Gens, Reply to the discussion by Zhang and Lytton on 'A new modelling approach for unsaturated soils using independent stress variables'. Canadian Geotechnics, 2008:45:17: p. 88-94.

28. G. Maier and T. Hueckel, Nonassociated and coupled flow rules of elastoplasticity for rock-like materials. Vol. 16. 1979. 77-92.

29. I.F. Collins and G.T. Houlsby, Application of thermomechanical principles to the modelling of geotechnical materials. Proceedings of the Royal Society of London. Series A: Mathematical, Physical and Engineering Sciences, 1997. 453:1964: p. 19752001.

30. K. Been and M.G. Jefferies, A state parameter for sands. Géotechnique, 1985. 35:2: p. 99-112.

31. D. Gallipoli, A. Gens, R. Sharma, and J. Vaunat, An elasto-plastic model for unsaturated soil incorporating the effects of suction and degree of saturation on mechanical behaviour. Géotechnique, 2003. 53:1: p. 123-135. 
32. A.R. Russell and N. Khalili, A unified bounding surface plasticity model for unsaturated soils. International Journal for Numerical and Analytical Methods in Geomechanics, 2006. 30:3: p. 181-212. 